\title{
O ITINERÁRIO DE TÂNATOS: A ANALÍTICA DO DASEIN E AS CONFORMAÇÕES UTÓPICAS EM MORTE E VIDA SEVERINA, DE JOÃO CABRAL DE MELO NETO
}

\section{Milton Rosendo Nascimento Júnior*}

Resumo: Firma-se este presente trabalho em uma perspectiva de leitura que enfatiza um centramento na questão do tanático como fator que irá deflagrar em Morte e Vida Severina, poema dramático do escritor pernambucano João Cabral de Melo Neto, as possibilidades existenciais que solidificam a disposição do ser-no-mundo como constante devenir e como elemento sintetizador tanto de um não-ser que lhe é intrínseco, quanto da idéia de negação da negação absoluta representada pela morte, posto que na própria descontinuidade de seu estar-lançado encontra estímulo para ir em busca de um ainda-não-ser que se lhe abre como um horizonte pleno de um poder-ser. A hermenêutica ontológica do filósofo alemão Martin Heidegger irá se associar aqui, respeitando-se as inevitáveis divergências de óptica conceptual, ao conceito de utopia a que se empenharam em estudar pensadores como Ernst Bloch e Karl Mannheim, entre outros.

Palavras-chave: Morte. Distopia. Dasein. Facticidade. Devir.

Disseminações do tanático: a morte onipresente

\section{A singularidade negativa de Severino}

Já ao principiar da narração em Morte e Vida Severina, no trecho intitulado "O retirante explica ao leitor quem é e a que vai", dá-se uma sutil relação de contigüidade entre o ser e o não-ser, contigüidade essa que se dilui ao ponto de uma quase indistinção entre ambos, posto que ao que tenta o protagonista delinear uma identidade ao se apresentar, fica subjacente à sua tentativa a idéia de um fracasso. Tal fracasso se evidencia por um apresentar que, na verdade, não apresenta. Observa-se que todo ato de apresentar é um expor, um mostrar, um tornar presente,

- Doutorando em Literatura Brasileira, Programa de Pós-Graduação em Letras e Lingüística, Universidade Federal de Alagoas. 
mas no discurso de Severino ou, aliás, do ente que se afigura como Severino, o que se estabelece é um tornar-se presente de modo parcial, marcado por dubiedades que ora o especificam, ora o descaracterizam em face a generalidades. Nesse mostrar-se, portanto, ocorre um encobrimento ontológico. A singularidade de Severino, pois, demonstra-se como negativa, já que exibe em sua estrutura uma ausência, uma abstenção, um ser decaído na impessoalidade cotidiana e que, logo, se constitui como um ser-com-os-outros em seu sentido impróprio. Veja-se, a seguir (MELO NETO, 2000, p. 45-6), o que diz Severino:

O meu nome é Severino, não tenho outro de pia.

Como há muitos Severinos. que é santo de romaria, deram então de me chamar

Severino de Maria; como há muitos Severinos com mães chamadas Maria, fiquei sendo o da Maria do finado Zacarias. Mas isso ainda diz pouco: há muitos na freguesia, por causa de um coronel que se chamou Zacarias e que foi o mais antigo senhor desta sesmaria. Como então dizer quem fala ora a Vossas Senhorias? Vejamos: é o Severino da Maria do Zacarias, lá da serra da Costela, limites da Paraíba.

Mas isso ainda diz pouco:

se ao menos mais cinco havia com nome de Severino

filhos de tantas Marias mulheres de outros tantos, já finados, Zacarias, vivendo na mesma serra magra e ossuda em que eu vivia. 
Esse ser-aí que, então, se manifesta no discurso de Severino não revela, de fato, quem é; afinal, toda nova informação que veicula para distinguir-se, para realçar a sua singularidade, é, posteriormente, mais um elemento que se soma para torná-lo apenas um entre tantos outros. Essa singularidade banalizada, que mais oculta do que expõe, inconcreta e, portanto, negativa, é o que denota a configuração da morte inserida na constituição ontológica de Severino. O não-ser lhe é algo intrínseco. Subcutaneamente ao que diz, Severino permite entrever uma identidade que se esgarça, à medida que se apercebe enquanto ser-no-mundo. Não obstante, delineia-se, através do fluxo dramático do poema de João Cabral de Melo Neto, um constante conflito ontológico em Severino que, ao colocá-lo em itinerância pelas trilhas donde salta a seus olhos de retirante a sempre ameaçadora inserção da morte, convida-o, a cada instante, a um modo de ser que se impele a um ainda-não-ser, a uma configuração de suas possibilidades ônticas para além das funestas perspectivas do contexto social e geográfico em que se encontra. Tal embate entre o desejo de poder-ser em Severino, em torno de um ainda-não-ser que parece sofrer um estreitamento mediante a ação entrópica da morte, nada mais é do que, senão, a representação da porfia ontológica do sujeito que se recusa a aceitar a idéia de um total esgotamento de suas possibilidades existenciárias, e, portanto, movido por uma esperança, move-se numa odisséia em busca de um continuun para o sentido de estar-no-mundo. Afirma-se, pois, que, no decorrer do texto, irá moldar-se em Severino o que Mannheim (1972, p. 216) refere como um estado de espírito utópico: "Um estado de espírito é utópico quando está em incongruência com o estado de realidade dentro do qual ocorre".

Um ser-aí severino: facticidade e de-cadência

O manifestar-se de Severino atribui-lhe um sentido ônticoontológico que decorre de um ente que se dá a conhecer, isto é, a presença, o ser-aí, e que, sendo, lança-se a um questionamento acerca de seu próprio ser. Esse acercar-se de si que ora clarifica, ora obscurece a noção de singularidade em Severino advém de um drama existencial que irrompe de um conhecer-se enquanto ser manifesto no mundo, um ser-com-o-mundo, mas também de não se reconhecer em seu sentido essencial e não-dissociável de si mesmo. O discurso de Severino aborda a noção de um ente à borda de seu ser a se questionar sobre a sua singularidade, pois o que diz de si pouco demonstra de si e, além 
disso, adicionado ao fato de estar-no-mundo, ocorre que sua individualidade parece dissolver-se ao ser junto com outros tantos, iguais a ele, também Severinos. Mas o que significa entender Severino tal como um ente? Faça-se compreender a acepção do termo ente por intermédio das palavras de Heidegger (2000, p. 32): "Chamamos de 'ente' muitas coisas e em sentidos diversos. Ente é tudo de que falamos, tudo que entendemos, com que nos comportamos dessa ou daquela maneira, ente é também o que e como nós mesmos somos."

Severino não é somente um ser que se manifesta, mas também a manifestação de um ser. Ao tentar exprimir-se como um ser que busca definir-se no que é, sendo, assume o privilegiado lugar do Dasein com relação aos demais entes. Mas o que significa, propriamente, entender Severino tal como Dasein? Em seu livro Ser e tempo, Heidegger (2000, p. 33) explicita o sentido desse termo:

Ora, visualizar, compreender, escolher, aceder a são atitudes constitutivas do questionamento e, ao mesmo tempo, modos de ser de um determinado ente, daquele ente que nós mesmos, os que questionam, sempre somos. [...]Esse ente que cada um de nós somos e que, entre outras, possui em seu ser a possibilidade de questionar, nós o designamos com o termo pre-sença. ${ }^{1}$

E mais adiante, Heidegger (2000, p. 38) complementa:

A pre-sença não é apenas um ente que ocorre entre outros entes. Ao contrário, do ponto de vista ôntico, ela se distingue pelo privilégio de, em seu ser, isto é, sendo, estar em jogo seu próprio ser. Mas também pertence a essa constituição de ser da pre-sença a característica de, em seu ser, isto é, sendo, estabelecer uma relação de ser com seu próprio ser. Isso significa, explicitamente e de alguma maneira, que a pre-sença se compreende em seu ser, isto é, sendo. É próprio deste ente que seu ser se lhe abra e com e por meio de seu próprio ser, isto é, sendo. A compreensão do ser é em si mesma uma determinação do ser da pre-sença. O privilégio ôntico que distingue a pre-sença está em ser ela ontológica.

1 Ou seja, o Dasein, o ser-aí. 
Ao estabelecer uma relação de ser com seu próprio ser, Severino acaba por desvelar a sua condição de ser-lançado-no-mundo, de estar jogado em um universo de condições sócio-históricas, geográficas e econômicas, e com as quais seu ser-aí, a sua pre-sença, interage. A facticidade impõe-se a Severino como um estar-certo de mover-se em um mundo hostil, agreste, em que seu ser-em constitui uma questão de sobrevivência meramente. A facticidade de Severino consiste em estarlançado a um contexto espacial de ordem negativa, onde o que se vê caracterizada é uma persistente marca de ausência, de privação, de um modo de ser que se mostra mais pelo que ele não é. Diante dessa espacialidade negativa, de que a seguir tratar-se-á, o personagem Severino assume um ser-junto-aos-outros, compartilhando com esses o mesmo destino de miserabilidade em que, a cada momento, na sua qualidade de ser sempre impendente, a morte vem cobrar o seu tributo:

Somos muitos Severinos

iguais em tudo na vida : na mesma cabeça grande que a custo é que se equilibra, no mesmo ventre crescido sobre as mesmas pernas finas, e iguais também porque o sangue que usamos tem pouca tinta.

E se somos Severinos iguais em tudo na vida, morremos de morte igual, mesma morte severina: que é a morte de que se morre de velhice antes dos trinta, de emboscada antes dos vinte, de fome um pouco por dia (de fraqueza e de doença é que a morte severina ataca em qualquer idade, e até gente não-nascida) (MELO NETO, 2000, p. 46). 
Esse ser-junto-aos-outros decorrente do ser-em, do estarlançado-no-mundo, não atribui ao ser-aí de Severino um poder-ser mais pleno, posto que a possibilidade da impossibilidade de existir representada pela morte encontra-se obnubilada, ofuscada pela deslembrança que se funda na public-idade da convivência cotidiana. A respeito disso, Heidegger (1996, p. 35-36) comenta:

A morte que é sempre minha, de forma essencial e
insubstituível, converte-se num acontecimento público,
que vem ao encontro no impessoal. O discurso assim
caracterizado fala da morte como um "caso" que
permanentemente ocorre. Ele propaga a morte como algo
sempre "real" mas lhe encobre o caráter de possibilidade
e os momentos que lhe pertencem de irremissibilidade e
insuperabilidade. Com essa ambigüidade, a pre-sença
adquire a capacidade de perder-se no impessoal, no
tocante a um poder-ser privilegiado, que pertence ao seu
ser mais próprio. O impessoal dá razão e incentiva a
tentação de encobrir para si o ser-para-a-morte mais
próprio.

Esse falar acerca da morte no discurso de Severino notabilizase por uma constatação da morte como um "fato real", mas não como uma possibilidade que abre para a pre-sença um poder-ser mais próprio, uma singularidade. Severino apenas integra a impessoalidade da convivência cotidiana na public-idade. A morte lhe pertence como um acontecimento que pode a qualquer instante vir a seu encontro, todavia, não lhe permite uma circunvisão existenciária que lhe faça apropriar-se de sua existência pela óptica da existencialidade, ou seja, de um existir enquanto antecipação de seu poder-ser mais próprio. O discurso de Severino, pois, está entranhado na mediania pseudoestabilizante do cotidiano e, por isso mesmo, acha-se enredado à impossibilidade de uma abertura ao poder-ser, já que, de certo modo, há uma certa circularidade discursiva que sempre coloca o personagem diante da morte em sua trajetória de retirante, mas trata-se apenas aqui de um estar-defronte-à-morte que encobre ao ser-aí, ao Dasein, um modo de ser que o direciona para um apoderar-se de suas possibilidades existenciais. A linguagem disponibiliza ao ser somente um repertório de coisas dominado por uma certa constância e regularidade que se manifesta sob a ótica do ser-em-comum da 
convivência no impessoal. Quanto a essa questão, avalia Benedito Nunes (1992, p. 103):

A linguagem não é uma capacidade específica que se agrega à sua existência. Ele a possui como modo de ser. "O Dasein tem linguagem (hat Sprache)", diz Heidegger. "O homem se mostra como ente que fala. Isto não significa que lhe seja peculiar a possibilidade de fonação, mas que este ente existe no modo da descoberta do mundo e do próprio Dasein". Mas pode-se também asseverar, inversamente, que a linguagem possui o Dasein. É que da forma de compreensão e de interpretação segundo a perspectiva do ser-em-comum, estabilizada na mediania do cotidiano, sob o domínio anônimo da gente, a comunicação transmite o que se tornou constante e regular: o estado público, que limita as possibilidades do discurso à reprodução do já compreendido e interpretado. $\mathrm{O}$ discurso decai numa atividade repetitiva e reflexa. Por espelhamento da interpretação dominante de todos, o discurso (die Rede) se transforma, de redundância em redundância, no falatório ou na parolagem (Gerede) como linguagem instrumentalizada. Tornando-se instrumento, a linguagem ganha a segurança de um meio estabilizado de comunicação, em que as significações, combinadas pelo valor comum das palavras que a gente usa, convertem-se na " moeda corrente da fala". Nesse estado público da linguagem, que prescreve até a maneira verbal de sentir, de pensar e de agir, a possibilidade originária de abertura do discurso cede lugar à possibilidade inversa de encobrimento do ser-no-mundo.

O ser-aí de Severino acha-SE num estado de ser-em impróprio porque não assume o controle de seu poder-ser e, ao lidar com o estarjunto e com o mundo das ocupações, acaba perdendo-se na publicidade do impessoal. O dissolvimento de um apropriar-se de si mesmo mais pleno, que ocorre com Severino, em um integrar-se à cotidianidade e aos outros caracteriza o que, na terminologia heideggeriana, denomina-se de-cadência. O Severino que emigra é um ser-aí sorvido pelo turbilhão de seu de-cair. O poder de tornar-se o que almeja the parece algo fora de si mesmo e inviabilizado pela 
ubiqüidade do não-ser, que lhe assedia e o incita a aceitar-se como serpara-a-morte.

A espacialidade negativa: paragens do não-ser

De um apresentar-se manifestadamente como ser-aí, em que nas entrelinhas já se permite vislumbrar o não-ser que desponta de uma singularidade negativa, Severino passa para uma atitude concreta, para uma ação que se define como um mover-se, um emigrar, que nada é senão, de um ponto de vista ontológico, um trilhar para a morte como possibilidade insuperável e irremissível. Esse mover-se coloca o protagonista diante de uma realidade espacial na qual o não-ser se acha entranhado, constituindo, pois, a precariedade pontilhada de sinais funestos do ambiente em que transita uma ampliação que perfaz, simbolicamente, um adensamento da possibilidade de uma impossibilidade de existir indiciada pela morte onipresente.

A construção de uma idéia de espacialidade em Morte e Vida Severina, pois, funda-se em uma reconstrução ôntica de um mundo povoado por supressões, por "coisas de não", pela noção de um locus amoenus ao reverso. A descrição que Severino faz de seu lugar de origem denota uma relação metafórica na qual o ambiente parece incorporar aspectos da compleição física de seus habitantes: "vivendo na mesma serra / magra e ossuda em que eu vivia" (MELO NETO, 2000, p. 46).

A espacialidade negativa em que se dá o estar-lançado de Severino propicia-lhe um ir ao encontro do não-ser através das muitas formas com que se lhe transfigura. A morte parece persegui-lo e, ao mesmo tempo, estar à sua frente. A espacialidade negativa do real circundante, no entanto, apenas reflete um modo de ser do ser-em, já que o ser-aí implica um ser-no-espaço. Esse estar-e-ser-no-espaço concernente ao Dasein recai na inalienabilidade de seu ser-com-omundo. A esse respeito, Heidegger (2000, p. 152) comenta o seguinte:

Ao atribuirmos espacialidade à pre-sença, temos evidentemente de conceber este "ser-no-espaço" a partir de seu modo de ser. Em sua essência, a espacialidade da pre-sença não é um ser simplesmente dado e por isso não pode significar ocorrer em alguma posição do "espaço cósmico" e nem estar à mão em um lugar. Ambos são 
modos de ser de entes que vêm ao encontro dentro do mundo. A pre-sença, no entanto, está e é "no" mundo, no sentido de lidar familiarmente na ocupação com os entes que vêm ao encontro dentro do mundo. Por isso, se, de algum modo, a espacialidade lhe convém, isso só é possível com base nesse ser-em.

E as palavras de Chauí, em prefácio a Heidegger (1999, p. 7), complementam-NO: "O homem seria, assim, um ser que se projeta para fora de si mesmo, mas jamais pode sair das fronteiras do mundo em que se encontra submerso. Trata-se de uma projeção no mundo, do mundo e com o mundo, de tal forma que o eu e o mundo são totalmente inseparáveis."

A realidade distópica do mundo circundante transmite ao serem do desafortunado retirante nordestino, de modo gradativo, um crescente angustiar-se perante a morte. Aos poucos, Severino passa a "emigrar" de um conceito de morte "corriqueira", decorrente de sua imersão na public-idade da convivência cotidiana, para o da morte como possibilidade mais própria da pre-sença e em que se lhe abre um poder-ser mais pleno a seu ser mais próprio.

O revoltar-se contra e o re-voltar-se para a morte

A constante proximidade da morte somada às escassas condições existenciais proporcionadas pelo mundo circundante conduzem Severino a um estranhamento que o leva a desconfiar da percepção da morte como um mero acontecimento público, que lhe vem ao encontro no impessoal. Começa a insurgir-se, então, contra essa possibilidade que lhe é a mais própria, irremissível e insuperável :

Desde que estou retirando

só a morte vejo ativa,

só a morte deparei

e às vezes até festiva ;

só a morte tem encontrado

quem pensava encontrar vida,

e o pouco que não foi morte

foi de vida severina

(aquela vida que é menos

vivida que defendida, 


\author{
e é ainda mais Severina \\ para o homem que retira ). \\ Penso agora : mas por que \\ parar aqui eu não podia \\ e como o Capibaribe \\ interromper minha linha? \\ (MELO NETO, 2000, p. 52-53)
}

Inicialmente, a experimentação da morte dos outros era apreendida pelo ser-aí como um fato "real", que vinha a seu encontro através do impessoal, como uma possibilidade mascarada por um ainda-não. Agora, transcorre um preocupar-se com a morte que não só o induz a um temor de deixar de viver como também um anseio irrefletido e auto-destrutivo de unir-se ao não-ser. A temporariedade do ser-no-mundo já se apresenta como um horizonte à condição de ser mais próprio para Severino, porém, uma forte comoção interior oriunda de seu ser-com-os-outros de-caído na indistinção da vida cotidiana o impele a uma solução imediata à aflição premente diante de seu poder-ser mais próprio: extinguir a própria vida. Esse revoltarse contra a morte acarreta em Severino um sentimento de cessação das possibilidades existenciais da vida e, portanto, não caracteriza o estado de angústia, de acordo com a concepção desse termo para Heidegger. Segundo esse pensador:
A angústia com a morte é angústia "com" o poder-ser mais próprio, irremissível e insuperável. O próprio ser- no-mundo é aquilo com que ela se angustia. Não se deve confundir a angústia com a morte com o temor de deixar de viver. Enquanto disposição fundamental da pre-sença, a angústia não é um humor "fraco", arbitrário e casual de um indivíduo singular, mas sim a abertura do fato de que, como ser-lançado, a pre-sença existe para seu fim. Assim, esclarece-se o conceito existencial da morte como para o poder-ser mais próprio, irremissível e insuperável. Com isso, ganha nitidez a delimitação frente a um mero desaparecer, a um mero finar ou ainda a uma "vivência" do deixar de viver (1996, p. 33). 
A distopia em que Severino habita o atinge como uma aporia em que a morte se lhe impõe não como abertura a um devir, mas como fechamento a um poder-ser dentro de sua circunvisão existenciária, estando-lhe vetada a possibilidade de antecipar-se a si mesmo, enquanto ser-para-o-fim, e construir um ser mais próprio, assenhoreando-se de seu destino. Assim sendo, numa outra passagem, novamente Severino se depara com a possibilidade de "vivenciar" o deixar-de-viver :

E chegando, aprendo que, nessa viagem que eu fazia, sem saber desde o Sertão, meu próprio enterro eu seguia.

Só que devo ter chegado adiantado de uns dias ; o enterro espera na porta : o morto ainda está com vida.

A solução é apressar a morte a que se decida e pedir a este rio, que vem também lá de cima, que me faça aquele enterro que o coveiro descrevia: caixão macio de lama, mortalha macia e líquida, coroas de baronesa junto com flores de aninga, e aquele acompanhamento de água que sempre desfila (que o rio, aqui no Recife, não seca, vai toda a vida) (MELO NETO, 2000, p. 69-70).

Esse revoltar-se contra a morte representa um estancamento das possibilidades da vida. Não direciona o ser-lançado para um vir-aser, a um devir, muito pelo contrário, encaminha-o a um não-ser mais rapidamente, posto que encobre para a pre-sença a conscientização do ser-para-o-fim, a finitude existencial do homem, como antecipação de 
um poder-ser mais pleno ao ser-aí. A solução se manifesta no falar de um outro personagem, Seu José, mestre carpina :

Severino, retirante, sou de Nazaré da Mata, mas tanto lá como aqui jamais me fiaram nada : a vida de cada dia cada dia hei de comprá-la (MELO NETO, 2000, p. 72).

O mestre carpina desvela para Severino que o re-voltar-se para a morte, ou seja, um voltar-se de novo para ela não mais como uma negação do poder-ser, mas sim como uma força de propulsão a esse poder-ser, consiste em um apropriar-se da vida por intermédio de um conviver com a morte como possibilidade mais própria. Carpina sabe que se apropriar de um existir mais pleno é somente viável através de uma aceitação da indeterminabilidade do quando da morte, mas sempre como uma possibilidade impendente. A vida que tem o carpina, ele a conquista diariamente em seu poder-ser.

O nascimento de uma criança inverte o processo de apresentação do ser-aí que se dá no início do poema dramático de João Cabral, por meio do personagem Severino: com Severino, o apresentar-se transcorria a partir de um revelar um determinado "é" do ente para, em seguida, dele mostrar um "não é" ; com a criança recémnascida, dá-se o contrário, isto é, um revelar do ente, em primeiro lugar, pelo que nele se aspectua como traços próprios de um "não é" para, somente depois, mostrar o que nele se manifesta como um determinado "é", ou seja, um modo de ser. Observe-se:

O meu nome é Severino, não tenho outro de pia.

Como há muitos Severinos, que é santo de romaria, deram então de me chamar Severino de Maria ; Como há muitos Severinos com mães chamadas Maria, fiquei sendo o da Maria do finado Zacarias. 
Mas isso ainda diz pouco:

há muitos na freguesia, por causa de um coronel que se chamou Zacarias e que foi o mais antigo senhor desta sesmaria (MELO NETO, 2000, p. 45).

O nome e ascendência de Severino, como se pode constatar, não consolidam a sua singularidade. O seu apresentar-se indicia um ser sorvido pela cotidianidade do impessoal. Sua afirmação como serno-mundo enfatiza um estar-lançado próximo à idéia de um não-ser constitutivo. Observe-se, pois, agora, o seguinte:

De sua formosura

deixai-me que diga :

é uma criança pálida,

é uma criança franzina, mas tem a marca de homem, marca de humana oficina.

- Sua formosura deixai-me que cante : é um menino guenzo como todos os desses mangues, mas a máquina de homem já bate nele, incessante.

- Sua formosura eis aqui descrita: é uma criança pequena, enclenque e setemesinha, mas as mãos que criam coisas nas suas já se adivinha (MELO NETO, 2000, p. 77-78).

Há, nesse procedimento de apresentação do recém-nascido, primeiramente, uma sempre exposição de suas categorias negativas ("criança pálida", "criança franzina", "menino guenzo", "criança pequena", "enclenque", "setemesinha") que, a seguir, é sucedida pelos atributos ou possibilidades que positivam o seu estar-lançado. Nesse contexto, a conjunção coordenativa adversativa "mas" condensa em si 
o marco dessas antinomias amalgamadas no cerne fenomênico do estar-no-mundo. Por intermédio desse elemento contrstivo da linguagem, pois, é que se pode entrever uma secundarização do nãoser pelo poder-ser.

De tânatos a eros

A morte que emigrava juntamente com Severino encontra o fim de seu itinerário no eclodir da vida. O poder-ser mais pleno, que se instaura a partir de um tornar-se o que é, sendo, abre-se para Severino, por intermédio do espetáculo de mais um ser que "saltou para dentro da vida" e das palavras finais do mestre carpina:

E não há melhor resposta

que o espetáculo da vida :

vê-la desfiar seu fio,

que também se chama vida,

ver a fábrica que ela mesma,

teimosamente, se fabrica,

vê-la brotar como há pouco

em nova vida explodida ;

mesmo quando é assim pequena

a explosão, como a ocorrida;

mesmo quando é uma explosão

como a de há pouco, franzina;

mesmo quando é a explosão

de uma vida severina

(MELO NETO, 2000, p. 80).

Severino encontra na continuidade do fenômeno vida um apaziguamento com o ser-para-a-morte que é. Diante dessa vida que "explode" em meio ao universo de supressões em que habita, essa distopia da realidade sertaneja do nordeste brasileiro a representar uma dimensão do real humano em que o lugar que lhe cabe é o lugarnenhum, a morte ganha a possibilidade de não mais ser encarada como o fim de todas as expectativas do homem, mas como uma força que rearranja o sentido existenciário do ser-no-mundo. A esse respeito, refere-se Bloch (1995, p. 1176-1177): 
Can we get around the final fear by its being no fear at all? In fact when a healthy person considers the end a quite different feeling sometimes comes to life. Fear is changed by a strange feeling of curiosity, by the desire to know what dying is all about. This emotion is aroused by the great change wich death in any case brings with it. Curiosity transforms the falling curtain into one which also parts and reveals. For it the end of life is at the same time the beginning of something wholly unprecedented, even if it is only nothingness. This curiosity can better itself to become a kind of wish for discovery and for knowledege, it looks forward to the act of dying as to revelation. [...] Expectation then intends death as a kind of journey, both into its own subject and into the overpowering mystery of existence. At the moment of 'departure' from life the veil of the incognito seems to it to fall from the subject, as does the so-called outer shell from the mystery of existence. From this point of view, any journey can antecipate an element of the final journey, an element of the northern but colourful night of death, of the extremest exoticism. ${ }^{2}$

2 Podemos circundar o medo final por absolutamente não ser medo? De fato quando uma pessoa saudável considera o fim um sentimento muito diferente, algumas vezes chega à vida. O medo é mudado por um estranho sentimento de curiosidade, pelo desejo de saber o que é morrer afinal. Essa emoção é despertada pela grande mudança que a morte, em qualquer caso, traz com ela. A curiosidade transforma a cortina que cai em algo que também separa e revela. Para ela, o fim da vida é, ao mesmo tempo, o início de algo inteiramente não-precedente, ainda que isso seja apenas nada. Essa curiosidade melhor pode, por si mesma, tornar-se uma espécie de desejo para o descobrimento e o conhecimento, ela anseia pelo ato de morrer como a uma revelação. (...). A expectativa então reserva a morte como um tipo de jornada, mas dentro de seu próprio sujeito e dentro do superpotente mistério da existência. Desse ponto de vista, qualquer jornada pode antecipar um elemento da jornada final, um elemento da setentrional mas colorida noite da morte, do mais extremo exoticismo. (Trad. de Sérgio Moura). 
Do novo ser que se desentranha da obscuridade do não-ser, surge-lhe uma motivação para novamente aceitar a sua existência como desafio a um poder-ser mais próprio, tal como um chamamento à reivindicação de sua singularidade. Esse poder-ser mais próprio que, no texto de João Cabral, afigura-se como um nascer para a esperança.

\section{Observações finais}

Este ser que se funda a partir de um despontar ôntico oriundo do discurso de Severino, que se caracteriza pela sua condição de seraí, de ser que se instaura como "projeção do mundo, no mundo e com o mundo", traz consigo em sua constituição ontológica uma manifestação, que não lhe é menos própria, do não-ser, enquanto serpara-a-morte. A morte, ou o não-ser, nasce juntamente com um manifestar-se como ser-no-mundo, por parte de Severino.

Esse não-ser que integra a singularidade negativa que constitui o ser-aí de Severino alastra-se para o seu ser-em constitutivo, contaminando, pois, o mundo em que se encontra como estar-lançado, como uma dimensão espacial onde se acham ampliadas as supressões possíveis a um poder-ser mais próprio.

Severino, enquanto ser-aí imerso na public-idade da convivência cotidiana no impessoal, inicialmente, toma a morte como um fato "real", mas que lhe parece sempre distante de seu ser mais próprio pela tranqüilizadora idéia de um ainda-não, de uma aceitação da morte como uma possibilidade, mas não em seu caráter de impendente.

O desespero de uma experimentação da existência como aporia coloca Severino diante da possibilidade de "vivenciar" o deixar-de-viver, de antecipar a própria morte, suicidando-se. O fenômeno da vida e as palavras de mestre carpina, entretanto, o põem diante de seu poder-ser mais próprio como desafio à sua existência, que pode se instituir a partir da noção de sua temporariedade.

A morte perfaz um percurso que finda somente no instaurar de um poder-ser, de um nascer para as próprias possibilidades, mas sempre se reconhecendo nessas um não dar-se à totalidade que é próprio do ser-para-o-fim da pre-sença, do Dasein. 
É nesse sentido, portanto, que se conclui que, no texto de João Cabral de Melo Neto, a morte instaura-se não puramente como força entrópica e desagregadora da frágil estrutura da existência severina, mas como princípio deflagrador de uma consciência utópica, mostrando-se, pois, como uma abertura para toda sorte de possibilidades implícitas ao estar-no-mundo.

Referências

BLOCH, Ernst. The principle of hope. Vol. three. Trans. Neville \& Stephen Plaice e Paul Knight. Massachusetts: MIT Press, 1995.

HEIDEGGER, Martin. Ser e tempo. Parte I. Tradução de Márcia de Sá Cavalcante. Petrópolis: Vozes, 2000. (Col. Pensamento Humano).

HEIDEGGER, Martin. Ser e tempo. Parte II. Tradução de Márcia de Sá Cavalcante. Petrópolis: Vozes, 1996. (Col. Pensamento Humano).

HEIDEGGER, Martin. Conferências e escritos filosóficos. Tradução de Ernildo Stein. São Paulo: Nova Cultural, 1999. (Col. Os pensadores).

MANNHEIM, Karl. Ideologia e utopia. Tradução de Sérgio Magalhães Santeiro. Rio de Janeiro: Zahar, 1972.

MELO NETO, João Cabral de. Morte e vida severina e outros poemas para vozes. Rio de Janeiro: Nova Fronteira, 2000.

NUNES, Benedito. Passagem para o poético: filosofia e poesia em Heidegger. São Paulo: Ática, 1992. 